\title{
Forum
}

\section{The Dead Cats of November}

A politician, standing beside his opponent at a debate, was smacked in the face by a big dead cat. A man in the crowd yelled, "Sorry! I meant that for the other guy!" The politician, ruefully rubbing his face, roared back, "I wish you'd meant it for me, and hit him!"

On November 8 , dead cats smacked Democrats from the Congress to the counties. As a Republican, I'm delighted. As a political scientist who studies elections, however, I wonder for whom the cats were really meant. In a series of recent publications, I have argued that voters choose based on ideology, not economics. The economy is the key to elections only when voters have choices, based on principles and values. This election was unusual because there were no choices, no positive appeals to values at all. As a result, many incumbents lost, though the economy is growing nicely.

My view is different from political orthodoxy, but can help explain what happened in the election. I want to consider three myths, and give a warning, about the American political system.

Myth 1: Campaigns should be about issues. Nonsense. Campaigns are about governing. Issues belong on the floor of Congress, in hearings, or votes on referenda. Elective office lasts for years, and officials make myriad decisions on issues not foreseen at the time of the election. As a result, a good campaign is a confrontation of ideologies, of broad visions of governance. The problem is not that our elections aren't about issues; rather, our elections aren't about anything! Shakespeare diagnosed the problem long ago: "The fool multitude, that choose by show, not learning more than the fond eye doth teach; which pries not to the interior ..."

Myth 2: Negative campaigning is destroying our political system. Perhaps, but why? There are only three strategies for a campaign: argue for the broad vision of your party, brag about what you gave your district, or sling mud at your opponent. For 20 years, Democrats have offered no broad vision of how to run the nation. Instead, they perfected the art of campaigning as congressional incumbents, emphasizing what Democrats do for districts. Republican congressional candidates, of course, have also offered no vision. They couldn't even brag, because challengers and minority-party incumbents can't pry much pork out of the system. The only strategy left for Republicans was bile and mudslinging.

What happened in 1994? Democrats tried to defend pork with no pretense of a legitimating vision for the spending, and they got smacked. Government grew enormously in the 1930s and 1960 s, but FDR and LBJ (arguably) told us why. Though one could disagree with the principles, at least principles were advanced. But without an ideological basis, negative campaigns always beat bragging on pork (ask Tom Foley!) because of an asymmetry in voters' hearing. "I am for you, trust me" is selfserving political tripe. "He is a cannibal, and worships Satan!", on the other hand, at least makes for good TV. The thing to remember is that mudslinging is just a symptom, not the problem. If either party develops a vision of governance voters share, attack ads will lose most of their impact.

Myth 3: The Democratic Party can only survive by moving to the center. This is obvious nonsense, because the center is where beaten parties go to die. The new Republican majority in Congress is working on a coherent platform, a set of principles. The party may fail to agree on all the elements, but the leadership sees clearly what must be done: commit to an ambitious and coherent conservative agenda. Democrats cannot possibly win by committing themselves to pragmatism and pork. They must answer the Republican challenge head on, or work on their résumes.

Finally, the warning: The stakes in the current political transformation are enormous. If neither party presents a coherent and positive philosophy of governance soon, we will enter a political Dark Age. Politicians can survive on attack ads, but a functioning democratic system cannot. Unless the parties become leadership organizations, from Washington to the grass roots of county commissions, our choices and our elections won't get better. The dead cats of November may turn out to be boomerangs, and we voters will be the ones rubbing our faces.

\section{Michael Munger \\ Director of the Master of Public Administration Program at UNC-Chapel Hill}

\section{Multiple Submissions: Worth Considering?}

In a brief article shortly to be published in the Behavioral and Brain Sciences, we argue the case for "multiple" journal submission. We propose that, rather than the present practice where would-be articles are sent to only one journal at a time, they be sent to perhaps two or three journals simultaneously (Somit and Peterson, in press).

That proposal was based on an analysis of $\mathbf{4 0}$ (admittedly nonrandom) recent submissions to some 30 journals-of which the great majority were in political science. We found that it took more than three months to get a decision on $60 \%$ of these items, that the median time for a definitive answer was four months, that the mean time was a 
bit more than five months-and that $17 \%$ took six months or more.

Since our "study," the available database has been greatly enriched by G. Bingham Powell's thoughtful and detailed analysis of the processing time required for $A P S R$ submissions (Powell 1994). For nearly 400 manuscripts received during the first 11 months of 199394 , he reports, the median decisional time was " 63 working days (88 total days), or about three months." He then goes on to say that "[W] hile we are not proud of these numbers. . . they seem to be acceptable by current standards in political science."

Powell is correct. Our own figures and a great deal of anecdotal evidence indicate that the $A P S R$ performs much better in this respect than do most of its sister disciplinary publications. Nonetheless, Powell's data also show that a bit more than $25 \%$ of the submissions must wait about four months, and another $25 \%$ from five to eight months, for an editorial determination.

However, the APSR accepts only about $10 \%$ of the papers submitted to it; even though most other politi- cal science journals have a somewhat higher acceptance rate, the overwhelming odds (we would estimate at least five to one) are that an item will be rejected. This, of course, leaves the author(s) facing another submission, another

lengthy waiting period, etc. And if, as is usually the case, repeated submissions are required before an item is accepted (or abandoned in despair by its author[s]), this process can easily stretch out over a couple of years. ${ }^{1}$

For a number of reasons, spelled out in the Behavioral and Brain Sciences essay, we think that a good case can be made for multiple submissions. They would greatly help authors while imposing very little additional burden on editors. Given that making available sound research to professionals as speedily as possible so that results do not become "stale" should be an important goal of journals, we believe that any dispassionate costbenefit analysis would certainly favor multiple submissions.

The $A P S R$, to repeat, is among the very best of the profession's journals in decisional time, not to say its willingness openly to ad- dress this issue. Nonetheless, Powell's data certainly support our suggestion that the profession seriously consider the merits of shifting to a practice, just as we already do with book proposals, of multiple rather than single, seriatim, article submissions.

\section{Albert Somit \\ Southern Illinois University}

Steven A. Peterson

Alfred University

\section{Notes}

1. In all fairness, we should note that a referee for an unnamed journal regarded this as by no means unreasonable. Ah, with what courage we bear the misfortune of others!

\section{References}

Powell, Jr., G. Bingham. 1994. “Report of the Managing Editor of the American Political Science Review," 1993-94. PS27(4):759-65.

Somit, Albert, and Steven A. Peterson. (in press). "Journal Response Time: A Case for Multiple Submission." Behavioral and Brain Sciences. 